\title{
Folate intake and bowel cancer risk
}

\author{
John C. Mathers
}

Received: 8 May 2009/Accepted: 14 May 2009/Published online: 5 June 2009

(C) Springer-Verlag 2009

\begin{abstract}
Folate is a B vitamin required for one-carbon transfer reactions including methylation of cell macromolecules including DNA and synthesis of the purines adenosine and guanosine and the pyrimidine thymidine. Epidemiological evidence suggests that diets providing higher amounts of folates lower the risk of colo-rectal cancer (CRC) and these observations are supported by plausible biological mechanisms. Inadequate folate supply results in DNA damage through (a) the incorporation of uracil (in place of thymidine) into DNA and subsequent unsuccessful attempts at DNA repair and (b) aberrant patterns of DNA methylation. However, human intervention studies using relatively large doses $(500-5,000 \mu \mathrm{g} / \mathrm{day})$ of folic acid (a synthetic form of folate) have provided no evidence of benefit in terms of adenoma recurrence. Indeed, there is some evidence of potential harm in increased risk of prostate cancer. Possible reasons for the apparent divergence in findings from the observational and intervention studies include the use of (unphysiologically) large doses of folic acid in the intervention studies whereas smaller intakes of food folates appeared to offer "protection" against CRC in case-control and prospective cohort studies. With intakes of folic acid greater than $400 \mu \mathrm{g} / \mathrm{day}$, unmetabolised folic acid appears in peripheral blood and there are suggestions that this folic acid may have adverse effects e.g. reduced cytotoxicity of Natural Killer cells. Until the benefit-risk relationship associated with mandatory fortification with folic acid has been clarified (and, in particular, the possible risk of
\end{abstract}

\section{J. C. Mathers $(\square)$}

Human Nutrition Research Centre,

Institute for Ageing and Health, Newcastle University,

William Leech Building, Framlington Place,

Newcastle on Tyne NE2 4HH, UK

e-mail: john.mathers@ncl.ac.uk inducing extra cases of bowel or other cancer), it would seem wise to delay further mandatory folic acid fortification.

Keywords Biomarker Bowel cancer - Folate .

Folic acid · Intervention · Polyp

\section{Biology of colo-rectal cancer}

All cancers are genetic diseases in the sense that they arise from, and contain, cells with genetic defects. These genetic defects include mutations, chromosomal abnormalities (loss, breakages, rearrangements and duplications), telomere defects and aberrant epigenetic marks. Recent evidence suggests that the initial defects occur in stem cells [3] and are transmitted to the progeny of these stem cells. The resulting abnormal gene expression provides the tumour cells with unique properties not shared with the normal cell from which it arose including enhanced proliferation, resistance to apoptosis and the capacity for metastasis [8]. Colo-rectal tumours (bowel cancer) arise from the columnar epithelium which lines this part of the gut and, in many cases, appear to develop along a pathway known as the adenoma-carcinoma sequence [22]. Loss of function of the tumour suppressor gene $A P C$ is an early event in the development of most (about 85\%) bowel cancers and is observed in aberrant crypt foci-the earliest histological lesion. Approximately $5-10 \%$ of adenomas appear to develop into carcinomas. Because of its importance in protection of the colo-rectal epithelium against tumour development, $A P C$ is known as the gatekeeper gene for this tissue. The encoded protein interacts with several other cytoplasmic proteins and has roles in a number of key cellular processes including the WNT signalling pathway. When APC is functioning normally, APC protein participates in a 
multi-protein complex which results in $\beta$-catenin phosphorylation and its degradation within the cytoplasm. However, when $A P C$ is silenced by mutation or by epigenetic mechanisms, $\beta$-catenin accumulates, is translocated to the nucleus binds to, and activates, the transcription factors TCF and LEF and switches on expression of oncogenes including $C-M Y C$ and CYCLIN D1 [1]. There is increasing evidence that aberrant epigenetic marks are important in tumourigenesis through silencing of tumour suppressor genes such as $A P C$ and of DNA repair genes e.g. $M L H 1$ and MGMT [9].

Folate and health

In 1931, a young British doctor wrote a letter to the British Medical Journal describing "tropical macrocytic anaemia" which she had observed commonly among poor pregnant women working in the textile factories of Bombay (now Mumbai) in India [29]. Importantly, she discovered that the condition could be alleviated, and prevented, by giving the women yeast extract. Thus began the research which culminated in the discovery of folate (a B vitamin) and its biochemical role in one-carbon transfer reactions. Healthy non-pregnant, non-lactating adult humans require approximately $200 \mu \mathrm{g}$ folate daily but there is good evidence that higher intakes before and during early pregnancy prevent most cases of neural tube defects (NTD) [19]. As a result of successful intervention trials with folic acid (a synthetic form of folate with high bioavailability), it is recommended that all women planning a pregnancy should take folic acid supplements (usually $400 \mu \mathrm{g}$ daily). However, because a large proportion of pregnancies are not planned, and the extra folate is needed in the first few weeks of pregnancy to protect against NTD, it was recommended that staple foods should be fortified with folic acid [19]. This public health intervention was adopted in the USA and Canada where the addition of $140 \mu \mathrm{g}$ folic acid/100 g cereal grain became mandatory from 1 January 1998 (voluntary fortification began in 1996). The result has been a substantial increase in the folate status of the whole population [20] which has been accompanied by a reduction in NTD [18].

Folate and bowel cancer

There is substantial epidemiological evidence that diets rich in plant foods and, especially, in vegetables and fruits (good sources of folate) are associated with lower risk of colorectal cancer (CRC) [28] Given its role in one-carbon transfer reactions and in the synthesis and methylation of DNA, a plausible mechanistic can be made for potential protection by folate against bowel cancer. Lower folate status may enhance CRC risk in a number of ways including:
- Uracil misincorporation into DNA when thymidine supply (Thymidine synthesis requires folate) is inadequate. This leads to futile cycles of attempted DNA repair which may result in DNA strand breaks [2] and genomic instability [6].

- Aberrant DNA methylation. This may include both genomic hypomethylation and hypermethylation of $\mathrm{CpG}$ islands in the promoter regions of some genes resulting in aberrant gene expression [11].

\section{Observational studies of folate intake and CRC risk}

A recent meta-analysis of five cohort studies and six casecontrol studies provides strong evidence of lower CRC risk in those consuming higher intakes of food-derived folate [23]. Overall, $\approx 25 \%$ reduction in risk was observed in both cohort and case-control studies but the evidence was more consistent for the cohort studies. In contrast, there was no significant effect of total folate intake (that from foods plus supplements) on bowel cancer risk for either type of study [23]. Folate in foods is likely to be largely as folates whereas the form in most supplements is folic acid. Whilst such observational studies suggest that higher intakes of food folate may protect against CRC, confounding by other factors (dietary and otherwise) cannot be excluded. Recent data from the Netherlands suggest that folate intake may influence the biology of tumour development. In male subjects, those with higher folate intakes were more likely $(P=0.008)$ to have colonic tumours containing APC mutations [5].

\section{Genetic polymorphisms, dietary interactions and CRC risk}

The enzyme 5, 10-methylenetetrahydrofolate reductase (MTHFR) plays a key role in folate metabolism through catalysing the conversion of 5, 10-methylenetetrahydrofolate to 5-methyltetrahydrofolate. The common polymorphism $677 C \rightarrow T$ in the MTHFR gene affects the activity of the encoded enzyme and, therefore, the supply of 5-methyltetrahydrofolate which is the major form of folate in plasma. Using a nested case-control design within the Physician's Health Study [15] observed that men with the $T T$ version of this polymorphism had only half the risk of those with the $C C$ variant. In addition, these authors reported that the apparent protection afforded by the $T T$ variant of MTHFR was enhanced among those with adequate folate status but was no longer evident in those consuming 1 or more alcoholic drinks per day $[15,24]$ reviewed 10 studies (4,000 cases) of associations between 
$M T H F R$ 677C $\rightarrow T$ polymorphism and CRC risk. In six of these studies, homozygosity for the $T$ allele was associated with lower CRC risk although the difference was statistically significant in one study only and marginally so in one other study. The evidence for any influence of other MTHFR polymorphisms, or for polymorphisms in other genes involved in folate metabolism, on CRC risk is much weaker because of smaller numbers of studies [24]. These authors noted the importance of developing methodology for investigating interactions between multiple genes and multiple environmental factors [24].

\section{Folic acid intervention trials}

All intervention trials designed to test the effect of raising folate intake on bowel cancer risk have used folic acid as the intervention agent with recurrence of adenomas as a surrogate endpoint. To have carcinoma as the endpoint would require much larger and/or longer studies because carcinomas occur much less frequently than adenomas. Cole et al. [4] reported the outcomes of such a doubleblind, placebo-controlled randomised clinical trial (RCT) in which men and women (mean age 57 years) with a recent history of colorectal adenomas were randomised in a $3 \times 2$ factorial design to aspirin $(0,81$ or $325 \mathrm{mg} /$ day $)$ and folic acid ( 0 or $1,000 \mu /$ day). Anyone with vitamin $B_{12}$ deficiency (defined as serum concentration $<162 \mathrm{pg} / \mathrm{ml}$ ) were excluded. First follow up occurred after 3 years and participants had the option to continue in the study for a further period (3 or 5 years). The primary outcome was occurrence of 1 more adenomas with advanced lesions, adenoma multiplicity and adverse events as secondary outcomes. Raised plasma folate concentration at follow up provided strong evidence of compliance with the intervention. There was no significant effect of folic acid supplementation on the primary endpoint but supplementation raised the risk of advanced lesions $(P=0.05)$ in the absence of aspirin treatment [4]. In addition, among adverse events, there were significantly $(P=0.01)$ more cases of prostate cancer in those given folic acid supplements [4]. Evidence of potential adverse effects of high intakes of folic acid on prostate cancer risk have emerged from other intervention studies investigating effects on cardiovascular endpoints but in which effects on other health outcomes have been recorded. For example, in the Heart Outcomes Prevention Evaluation (HOPE2) study, where 5,522 people aged $>55$ years were given $2,500 \mu \mathrm{g}$ folic acid/day (together with vitamins $\mathrm{B}_{6}$ and $\mathrm{B}_{12}$ ) for 5 years, there were more cases of both colon and prostate cancer among those randomised to the vitamins but the differences were not statistically significant [14].
More recently, Logan et al. [13] have reported the outcomes of a further colorectal adenoma recurrence trial. In this multi-centre, double-blind RCT, 853 patients with a previous adenoma $>0.5 \mathrm{~cm}$ were randomised in a $2 \times 2$ factorial design to folic acid $(500 \mu \mathrm{g} /$ day $)$ or aspirin (300 mg/day) and the primary outcome was colorectal adenoma. After 3 years treatment there were no significant effects of either agent on the proportion of participants who developed adenomas [13].

\section{Gene-folate interactions in intervention studies}

Given the apparent interaction between folate status, or alcohol consumption, and MTHFR $677 C \rightarrow T$ polymorphism on risk of CRC [15], it might be anticipated that the effects of folic acid supplementation on colorectal adenoma recurrence would be modulated by genotype. This hypothesis was tested by Levine et al. [12] using data from their double-blind placebo-controlled intervention with $1,000 \mu \mathrm{g} /$ folic acid per day in which genotype for 2 MTHFR polymorphisms viz. $677 C \rightarrow T$ and $1298 A \rightarrow C$ was determined. Neither polymorphism was associated with adenoma recurrence and there was no evidence that the effect of folic acid supplementation differed by genotype [12]. The hypothesis that there are important dietgenotype interactions on carcinoma risk which are not reflected in studies of adenoma recurrence remains to be tested by appropriate intervention studies.

\section{Biomarker and animal model studies}

Van Den Donk et al. [27] carried out a RCT in 86 patients with a history of sporadic colorectal adenomas. The volunteers were randomised to consume either $5,000 \mu \mathrm{g}$ folic acid $+1,000 \mu \mathrm{g}$ vitamin $\mathrm{B}_{12}$ per day or placebo. Rectal mucosal biopsies were collected at baseline and after 6 months intervention for measurement of uracil misincorporation into DNA and for assessment of promoter methylation of a panel of cancer-related genes (MGMT, MLH1, P14, P16, RASSF1A and APC). Surprisingly, after the vitamin intervention, there was higher $(P=0.16)$ uracil concentration in DNA and the odds ratio for increased promoter methylation was also greater $(P=0.08)$ [27]. These results suggested that there was no evidence of benefit but some evidence of possible adverse effects on bowel cancer risk with this high dose supplementation in people with a history of polyps. Further, this study found that the effects of the intervention were similar in those with the $C C$ and $T T$ versions of the MTHFR $677 C \rightarrow T$ polymorphism [27]. 
Several mouse models have been developed with truncating mutations in the $A p c$ gene which give rise spontaneously to multiple intestinal neoplastic lesions akin to the human disease familial adenomatous polyposis [7]. In Min mice (which have a STOP mutation at codon 850 in the $A p c$ gene), we have observed that reducing the folate intake to below normal for 10 weeks from weaning reduced tumour burden significantly [17]. In this study, the effect was confined to female mice and there was a significant $(P=0.028)$ gender $\times$ diet interaction [17].

\section{Does increased folic acid intake through food fortification alter bowel cancer risk?}

The introduction of mandatory folic acid fortification of foods in N. America as a public health strategy to lower risk of NTDs provides a large scale, natural experiment of the health effects of enhanced folic acid intake. Inspection of changes in CRC rates before and after the introduction of mandatory fortification showed a steady fall in rates until around 1995-1996, an apparent increase over the next few years, followed by a return to pre-1995 rates of decline [16]. The patterns of change were very similar in both the USA and Canada [16]. At first sight this "blip" in CRC rates, coincident with the introduction of mandatory folic acid fortification, is prime facia evidence of a possible adverse effect but the apparent increase might be explained by confounders such as an increase in the frequency of colonoscopy among N. Americans at higher risk of CRC. No such change in colonoscopy frequency has been recorded and the authors concluded, cautiously, that the observed "blip" was evidence of a possible (temporary) adverse effect of folic acid fortification [16].

\section{Fate of folic acid in humans}

Given the apparent beneficial effects of higher intakes of food folate in protecting against bowel cancer in observational studies but the lack of evidence of benefit (and, indeed, fragmentary evidence of possible harm) in intervention studies with folic acid, it is important to consider whether higher intakes of folic acid per se rather than of natural food-derived folates could be contra-indicated particularly in those at greater CRC risk. It is clear that supplementation with folic acid in humans raises both circulating concentrations of folate and the folate content of tissues including the colo-rectal mucosa [21]. However, recent studies have shown that not all ingested folic acid is metabolised to 5-methyl tetrahydrofolate (THF) which had been supposed on the basis of rodent studies and studies in cell culture [30]. Sweeney et al. [25] fed healthy human subjects bread containing various amounts of folic acid and observed unmetabolised folic acid in serum with doses of $200 \mu \mathrm{g}$ folic acid twice daily. In additional investigation of the Framingham Offspring Cohort showed significantly higher concentration of folic acid in plasma collected after, compared with before, fortification with folic acid became mandatory in the USA [10]. It appears that, unlike in rodents, folic acid is metabolised to dihydrofolate and then to 5-methyl THF predominantly in the human liver and that the activity of the converting enzyme, dihydrofolate reductase, in human hepatocytes is relatively low so that with higher intakes of folic acid, unmetabolised folic acid "spills over" into the peripheral circulation [30]. The consequences, if any, of the appearance of folic acid in the post-hepatic circulation are not understood but there is some evidence that this may lead to reduced cytotoxicity of Natural Killer (NK) cells [26].

\section{Summary and priorities for further research}

In observational studies, higher intakes of food folates appear to protect against bowel cancer but it is not known whether this association is causal and such observational studies are subject to confounding by both dietary and nondietary factors. There is no evidence of benefit from large doses of folic acid in preventing colorectal adenoma recurrence. Conversely, there is preliminary evidence that supplementation and/or fortification with folic acid may enhance carcinoma development in those at higher risk. Greater clarity about the consequences, if any, for development of the common cancers will emerge from metaanalysis of secondary endpoints from the recent, and ongoing, folic acid intervention trials for primary and secondary CVD prevention. Note that these intervention trials have used doses of folic acid (500-5,000 $\mu \mathrm{g} / \mathrm{day})$ which are considerably higher that the known needs of nonpregnant, non-lactating adults $(200 \mu \mathrm{g} / \mathrm{day})$ or, indeed, the likely intakes of total folate in most people exposed to mandatory folic acid fortification. It appears possible that the species difference in folic acid metabolism between rodents and humans may mean that humans are exposed to unmetabolised folic acid when consuming moderately high amounts of folic acid ( $>400 \mu \mathrm{g} /$ day). The factors (genetic and otherwise) which influence folic acid metabolism to 5-methyl TFH in the human liver and, hence, the extent of apparent "spill over" of unmetabolised folic acid together with potential adverse sequelae are clear priorities for further research. In the meantime, it is important that effective public health measures are in place to ensure that women planning (or at risk of) a pregnancy have adequate folate intakes. Given the high rates of unplanned pregnancies, it seems unlikely that the current public health 
strategy of exhorting women to take folate supplements will be sufficient to meet the needs of this vulnerable group. Until the benefit-risk relationship associated with mandatory fortification with folic acid has been clarified (and, in particular, the possible risk of inducing extra cases of bowel or other cancer), it would seem wise to delay further mandatory folic acid fortification. This delay provides an excellent opportunity for innovative research on alternative strategies for ensuring that pregnant women have adequate folate intakes which avoid unintended consequences for other groups in the population.

Acknowledgments Research on folate and bowel cancer in my laboratory has been funded by the Food Standards Agency (N12002/ 7) and by the World Cancer Research Fund (2001/37).

Conflict of interest statement None.

\section{References}

1. Aoki K, Taketo MM (2007) Adenomatous polyposis coli (APC): a multi-functional tumor suppressor gene. J Cell Sci 120:33273335

2. Blount BC, Mack MM, Wehr CM, Macgregor JT, Hiatt RA, Wang G, Wickramasinghe SN, Everson RB, Ames BN (1997) Medical Sciences Folate deficiency causes uracil misincorporation into human DNA and chromosome breakage: implications for cancer and neuronal damage. Proc Natl Acad Sci USA 94:3290-3295

3. Boman BM, Huang E (2008) Human colon cancer stem cells: a new paradigm in gastrointestinal oncology. $\mathrm{J}$ Clin Oncol 26:2828-2838

4. Cole BF, Baron JA, Sandler RS, Haile RW, Ahnen DJ, Bresalier RS, McKeown-Eyssen G, Summers RW, Rothstein RI, Burke CA, Snover DC, Church TR, Allen JI, Robertson DJ, Beck GJ, Bond JH, Byers T, Mandel JS, Mott LA, Pearson LH, Barry EL, Rees JR, Marcon N, Saibil F, Ueland PM, Greenberg ER (2007) Folic acid for the prevention of colorectal adenomas: a randomized clinical trial. J Am Med Assoc 297:2351-2359

5. De Vogel S, Van Engeland M, Lüchtenborg M, De Bruïne AP, Roemen GM, Lentjes MH, Goldbohm RA, Van Den Brandt PA, De Goeij AF, Weijenberg MP (2006) Dietary folate and APC mutations in sporadic colorectal cancer. J Nutr 136:3015-3021

6. Duthie SJ, Mavrommatis Y, Rucklidge G, Reid M, Duncan G, Moyer MP, Pirie LP, Bestwick CS (2008) The response of human colonocytes to folate deficiency in vitro: functional and proteomic analyses. J Proteome Res 7:3254-3266

7. Fodde R, Smits R, Clevers H (2001) APC, signal transduction and genetic instability in colorectal cancer. Nat Rev Cancer 1:55-67

8. Hanahan D, Weinberg RA (2000) The hallmarks of cancer. Cell 100:57-70

9. Jones PA, Baylin SB (2002) The fundamental role of epigenetic events in cancer. Nat Rev Genet 3:415-428

10. Kalmbach RD, Choumenkovitch SF, Troen AM, D'Agostino R, Jacques PF, Selhub J (2008) Circulating folic acid in plasma: relation to folic acid fortification. Am J Clin Nutr 88:763-768

11. Kim YI (2005) Nutritional epigenetics: impact of folate deficiency on DNA methylation and colon cancer susceptibility. J Nutr 135:2703-2709
12. Levine AJ, Wallace K, Tsang S, Haile RW, Saibil F, Ahnen D, Cole BF, Barry EL, Munroe DJ, Ali IU, Ueland P, Baron JA (2008) MTHFR genotype and colorectal adenoma recurrence: data from a double-blind placebo-controlled clinical trial. Cancer Epidemiol Biomarkers Prev 17:2409-2415

13. Logan RFA, Grainge MJ, Shepherd VC, Armitage NC, Muir KR (2008) Aspirin and folic acid for the prevention of recurrent colorectal adenomas. Gastroenterology 134:29-38

14. Lonn E, Yusuf S, Arnold MJ, Sheridan P, Pogue J, Micks M, McQueen MJ, Probstfield J, Fodor G, Held C, Genest J Jr (2006) Homocysteine lowering with folic acid and B vitamins in vascular disease. N Engl J Med 354:1567-1577

15. Ma J, Stampfer M, Giovannucci E, Artigas C, Hunter DJ (1997) Methylenetetrahydrofolate reductase polymorphism, dietary interactions, and risk of colorectal cancer. Cancer Res 57:1098-1102

16. Mason JB, Dickstein A, Jacques PF, Haggarty P, Selhub J, Dallal G, Rosenberg IH (2007) A temporal association between folic acid fortification and an increase in colorectal cancer rates may be illuminating important biological principles: a hypothesis. Cancer Epidemiol Biomarkers Prev 16:1325-1329

17. McKay JA, Williams EA, Mathers JC (2008) Gender-specific modulation of tumorigenesis by folic acid supply in the Apc+l Min mouse during early neonatal life. Br J Nutr 99:550-558

18. Mills JL, Signore C (2004) Neural tube defect rates before and after food fortification with folic acid. Birth Defects Res A Clin Mol Teratol 70:844-845

19. MRC Vitamin Study Research Group (1991) The lancet, vol 338, pp 131-137

20. Pfeiffer CM, Caudill SP, Gunter EW, Osterloh J, Sampson EJ (2005) Biochemical indicators of B vitamin status in the US population after folic acid fortification: results from the National Health and Nutrition Examination Survey 1999-2000. Am J Clin Nutr 82:442-450

21. Powers HJ, Hill MH, Welfare M, Spiers A, Bal W, Russell J, Duckworth Y, Gibney E, Williams EA, Mathers JC (2007) Responses of biomarkers of folate and riboflavin status to folate and riboflavin supplementation in healthy and colorectal polyp patients (the FAB2 study). Cancer Epidemiol Biomarkers Prev $16: 2128-2135$

22. Rajagopalan H, Nowak MA, Vogelstein B, Lengauer C (2003) The significance of unstable chromosomes in colorectal cancer. Nat Rev Cancer 3:695-701

23. Sanjoaquin MA, Allen N, Couto E, Roddam AW, Key TJ (2005) Folate intake and colorectal cancer risk: a meta-analytical approach. Int J Cancer 113:825-828

24. Sharp L, Little J (2004) Polymorphisms in genes involved in folate metabolism and colorectal neoplasia: a HuGE Review. Am J Epidemiol 159:423-443

25. Sweeney M, McPartlin J, Scott J (2007) Folic acid fortification and public health: Report on threshold doses above which unmetabolised folic acid appear in serum. BMC Public Health $7: 41$

26. Troen AM, Mitchell B, Sorensen B, Wener MH, Johnston A, Wood B, Selhub J, McTiernan A, Yasui Y, Oral E, Potter JD, Ulrichy CM (2006) Unmetabolized folic acid in plasma is associated with reduced natural killer cell cytotoxicity among postmenopausal women. J Nutr 136:189-194

27. Van Den Donk MD, Pellis L, Crott JW, Van Engeland M, Friederich P, Nagengast FM, Van Bergeijk JD, De Boer SY, Mason JB, Kok FJ, Keijer J, Kampman E (2007) Folic acid and vitamin B-12 supplementation does not favorably influence uracil incorporation and promoter methylation in rectal mucosa DNA of subjects with previous colorectal adenomas. J Nutr 137:2114-2120 
28. WCRF (2007) World Cancer Research Fund Expert Report http://www.wcrf-uk.org/research_science/expert_report.lasso

29. Wills L (1931) Pernicious anaemia of pregnancy and tropical anaemia with special reference to yeast as curative agent. Br Med J 1:1059-1064
30. Wright AJA, Dainty JR, Finglas PM (2007) Folic acid metabolism in human subjects revisited: potential implications for proposed mandatory folic acid fortification in the UK. Br J Nutr 98:667-675 